

\title{
Editorial
}

\section{Promoting the next wave of paramedic researchers}

\author{
Malcolm Boyle PhD'
}

\author{
Affiliation: \\ 'Monash University, Victoria
}

This issue is a special student-led research issue and it is the second time the Australasian Journal of Paramedicine (AJP) has devoted an issue solely to student-led research. In 2014, the Student Paramedics Australasia (SPA) Conference was held on the Gold Coast, Queensland, Australia in conjunction with the Paramedics Australasia International Conference where the AJP student issue (1) was published to coincide with the first day of the 2014 SPA conference. Like the student issue in 2014, this issue has been published to coincide with the first day of the 2015 SPA conference in Melbourne, Victoria, Australia.

The criteria for having an article published in a student issue is that the research work must have been predominately undertaken by the student in either their undergraduate course or honours program with the student as the lead author.

One of the aims of the AJP is to publish pre-hospital related research that other journals will not publish, for a variety of reasons, so research findings are not lost in the ether and to ensure growth of the pre-hospital research knowledge base, especially in the Australasian context.

In some cases students are completing their undergraduate degree with two publications and their honours program with five or more publications. These graduate paramedics are the future researchers for the new profession and hence need to be supported in all aspects of the research process. Publishing their work allows them to experience the process of scientific writing and the publishing process, in a supported environment, plus the discipline/profession does not lose valuable research findings.

There are journals who are solely committed to publishing research undertaken and written by undergraduate students, some of these include Reinvention: an International Journal of Undergraduate Research (2), the Surrey Undergraduate Research Journal (3), the Journal of Undergraduate Research in Physics (4) and the Journal of Young Investigators (5). These journals demonstrate the importance placed on student lead research by other professions and disciplines.

In the future I hope students can have a bigger say in producing the student issue that will then lead onto greater participation in scientific publishing.

Dr Mal Boyle

Editor

Australasian Journal of Paramedicine

\section{References}

1. Available at: http://ajp.paramedics.org/index.php/ajp/issue/view/2

2. Available at: www2.warwick.ac.uk/fac/cross_fac/iat//reinvention

3. Available at: https://surj.surrey.ac.uk/ojs/index.php/surj)

4. Available at: www.jurp.org

5. Available at: www.jyi.org 